\title{
Mapping the thematic evolution in Communication over the first two decades from the 21st century: A longitudinal approach
}

How to cite (APA):

Hernandez-Cruz, N. (2021).

Mapping the thematic evolution in

Communication over the first two decades from the 21st century: A longitudinal approach.

Iberoamerican Journal of Science Measurement and

Communication; 1(3), 1-10.

https://doi.org/10.47909/ijsmc.88

Received: 7-05-2021

Accepted: 16-08-2021

Handling Editor: Carlos Luis González-Valiente

\section{Copyright: () 2021}

Hernandez-Cruz. This is an open-access article distributed under the terms of the CC BY-NC 4.0 license, which permits copying and redistributing the material in any medium or format, adapting, transforming, and building upon the material as long as the license terms are followed.
Netzahualcoyotl Hernandez-Cruz1

\section{ABSTRACT}

This study offers an overview of the thematic structure in Communication during the first two decades of the 21st century, 2001-2010 and 2011-2020. The included work mapped author keywords and keywords plus of citable articles published in the Journal Citation Reports-2019 edition. A longitudinal perspective was employed to visualize the thematic evolution. Four predominant thematic areas were evidenced in both decades: (1) Speech and Language, (2) Commercial Communication, (3) Health Communication, and (4) Organizational Communication. There were four topics reflecting the formation of substantial research areas during the second decade, such as (1) Science Communication, (2) Scholarly Publishing, (3) Mental Health and Interpersonal Relationships, and (4) Crime and Violence. In general, from the first to the second decade, the technological dimension ceased to be predominant, and instead, there was a more significant presence of themes that responded to a socio-psychological dimension.

Keywords: Communication; Science mapping; Co-word analysis; Bibliometrics; Journal Citation Reports; Web of Science

\section{INTRODUCTION}

The field of Communication has considerable historical wealth promoted by academic organizations that have contributed to reaching a high level of disciplinary development during the 21st century (Rains et al., 2020). Lately, attention has been paid to this field of knowledge

1 Ulster University, Belfast, UK. Email: n.hernandez-cruz@ulster.ac.uk, ORCID: 0000-0002-3603-4806. 
to reveal its thematic structure (Chan \& Grill, 2020). Many researchers have relied on the benefits provided by bibliometric techniques to examine various conceptual, theoretical, and socio-intellectual traits. Montero-Díaz et al. (2018) consider that, due to the high volume of studies on the area, the analysis of its conceptual evolution must be carried out using bibliometric techniques and science mapping.

The number of communication journals from different countries has increased in recent times, many of which have also been incorporated into multidisciplinary databases such as Web of Science (WoS) and Scopus. Therefore, many bibliometric studies have used individual journals at the aggregation level. Titles of great trajectory have been examined, as has been the case of the International Journal of Advertising (Donthu, 2021), Journal of Communication (Lin \& Lee, 2012), Profesional de la Información (López-Robles et al., 2019), Communication Monographs, and Human Communication Research (Feeley, 2008; Beatty, 2012), just to mention a few. Regardless of the relevance of a journal itself for the field, studies at this aggregation level only show patterns limited to the source under study, where the set of homologous sources representing the field is discarded. On the other hand, some studies have examined communication sub-themes, as well as related topics such as environmental communication (Comfort \& Park, 2018), social capital (Lee \& Sohn, 2016), corporate social responsibility (Ji, 2021), institutional excellence (Feng, 2020), social media (van Osch \& Coursaris, 2014), organizational communication (Miguez-Gonzalez \& Costa-Sanchez, 2019), digital marketing communication (Kim, 2019), and health communication (Mheidly \& Fares, 2020).

Although there are antecedents of articles exploring the thematic structure of communication using a comprehensive coverage of journals and temporal space (Lee, 2016; Montero-Díaz et al., 2018), this study seeks to offer an up-to-date overview of the thematic structure of this field during the first two decades of the 21st century. The following research questions (RQ) will be answered throughout the paper:

- RQ1: What is the overall thematic structure in Communication from 2001-2020?

- RQ2: How has the field of Communication evolved from 2001-2010 and 2011-2020?

\section{MATERIALS AND METHODS}

The study consisted of articles published from 2001 to 2020. The study was limited to 92 journals listed in the Journal Citation Reports (JCR)-2019 edition in the Communication category of WoS. The document typologies considered in the study were article, review, and conference paper. This study consisted of an overall of 49,363 documents (see Table 1).

\begin{tabular}{ll}
\hline Description & Results \\
\hline & General information \\
Time coverage & $2001-2020$ \\
Journals & 91 \\
Documents & 49,363
\end{tabular}




\begin{tabular}{lll}
\hline Description & Results \\
\hline \multicolumn{3}{l}{ Document types } \\
Article & 46,995 \\
Article; conference paper & 1,399 \\
Review & 969 \\
& Document contents & \\
& & 19,336 \\
Keyword Plus & & \\
Author keywords & & \\
\hline
\end{tabular}

Table 1. A summary of the study dataset.

The variables used in the study were "Author Keywords" and "Keywords Plus", which underwent a rigorous disambiguation process to eliminate variants of the same term, as well as irrelevant terms. To answer RQ1, bibliometric networks were created from the keywords of all the sampled articles. These keywords were processed considering their frequency. Grouping techniques were applied using the VOS (visualization of similarities) algorithm (van Eck et al., 2010), by which the closest terms were mapped into clusters. These keyword clusters represented research themes and they were differentiated by color.

A longitudinal perspective was used to analyze thematic evolution (RQ2), in this case by dividing the analysis into the decades 2001-2010 and 2011-2020. Regarding the parameters for generating thematic maps, only those keywords with a frequency $\geq 10$ were selected. A minimum of 20 words per cluster was also defined, an amount considered relevant to identify a research topic. This procedure allowed to identify the changes in the thematic composition of the communication field from the final qualitative analysis of the clusters formed in each decade.

\section{RESULTS}

\section{Thematic structure in Communication during the decade of 2001-2010}

From the parameters defined in the methodological section, a thematic map was generated consisting of 1,120 words grouped into 10 clusters (see Figure 1 and Table 2). The thematic clusters identified during the first decade are described below.

- Cluster 1 "Technology and communication in social networks". This is the largest cluster on the entire map, made up of 398 terms. Here the emphasis on technology and online environments stands out.

- Cluster 2 "Gender studies". This cluster is made up of 176 terms and refers to gender studies.

- Cluster 3 "Speech and language". This cluster is made up of 163 terms and deals with studies on speech and language.

- Cluster 4 "Media and addiction". This cluster has to do with addictive behavior and the 
media. The presence of specific terms shows that the school context and the adolescent subject are the most explored due to terms such as adolescent, student, youth, school, college student, college, and adolescent smoking.

- Cluster 5 "Commercial communication". This cluster, made up of 99 terms, deals with the promotion and advertising in the media.

- Cluster 6 "Health communication". This cluster, made up of 94 keywords, reflects research on communication in the health context.

- Cluster 7 "Political and scientific communication". This cluster, made up of 79 terms, represents studies on political communication and scientific communication. On the one hand, terms like political participation, campaign coverage, political knowledge, presidential campaign, election, voter, candidate, presidential election, political socialization, vote, and presidential debate evidence the topic of political communication. At the same time, science communication is evidenced by nanotechnology, science communication, biotechnology, public understanding, science, and scientist.

- Cluster 8 "Computer-mediated communication". Cluster is composed of 39 words that highlight communication through mobile and computer technologies.

- Cluster 9 "Organizational communication". This cluster comprises 34 keywords that reflect the area of communication studies in the business environment.

- Cluster 10 "Racism and the media in the United States". This is the last cluster, composed of 34 keywords and emphasizing the North American context. It is a cluster that refers to racism and violence in the United States.

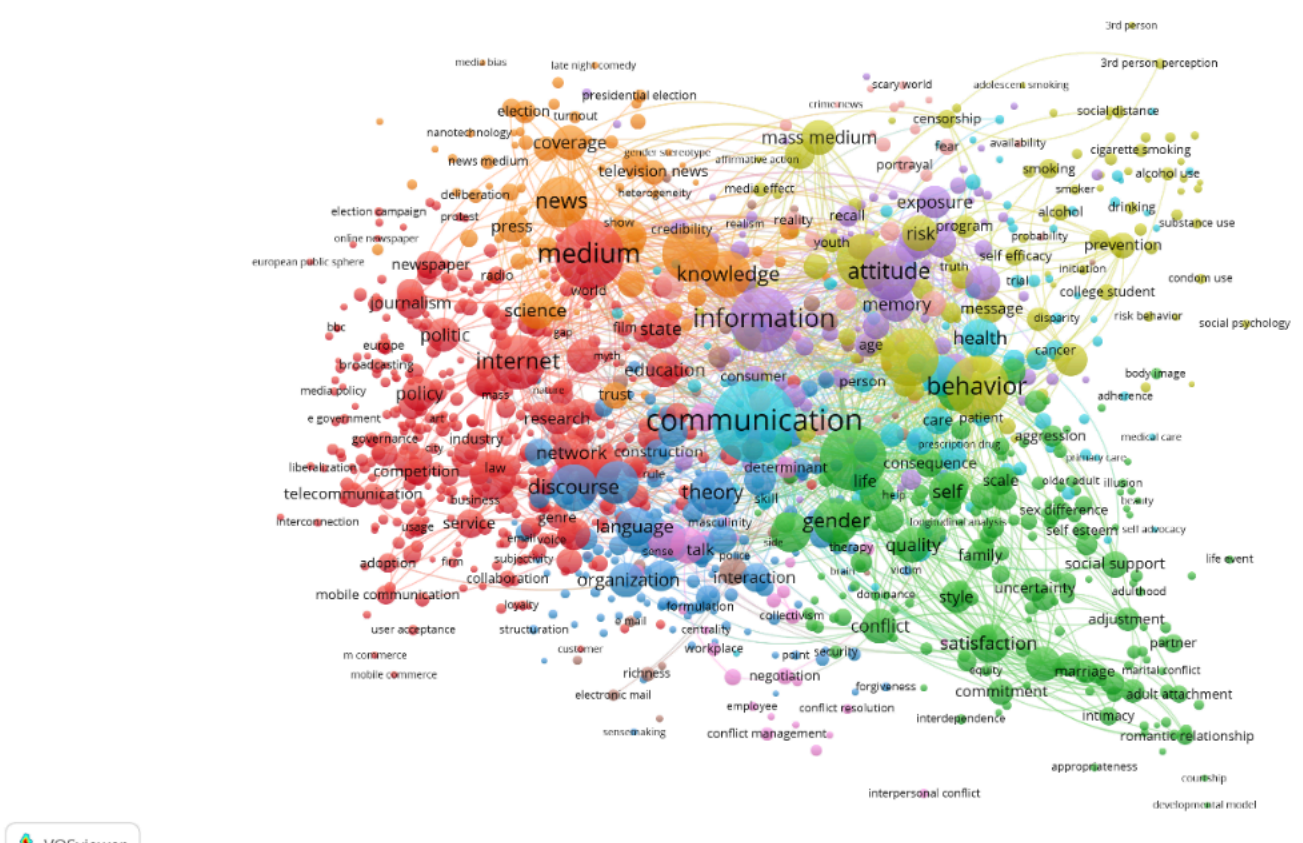

Figure 1. Thematic map of the field Communication during the decade 2001-2010.

Cluster Topic

$1 \quad$ Technology and communication
Keywords Top co-occurring keywords

398
Medium, Internet, Technology, Analysis, 


\begin{tabular}{|c|c|c|c|}
\hline Cluster & Topic & Keywords & Top co-occurring keywords \\
\hline & in social networks & & Culture \\
\hline 2 & Gender studies & 176 & $\begin{array}{l}\text { Model, Gender, Strategy, Satisfaction, } \\
\text { Self }\end{array}$ \\
\hline 3 & Speech and language & 163 & $\begin{array}{l}\text { Discourse, Theory, Identity, Language, } \\
\text { organization }\end{array}$ \\
\hline 4 & Media and addiction & 104 & $\begin{array}{l}\text { Behavior, Perception, Impact, Risk, } \\
\text { mass medium }\end{array}$ \\
\hline 5 & Commercial communication & 99 & $\begin{array}{l}\text { Information, Attitude, Memory, Response, } \\
\text { involvement }\end{array}$ \\
\hline 6 & Health communication & 94 & $\begin{array}{l}\text { Communication, Woman, Health, Life, } \\
\text { decision making }\end{array}$ \\
\hline 7 & $\begin{array}{l}\text { Political and scientific } \\
\text { communication }\end{array}$ & 79 & $\begin{array}{l}\text { Television, News, Knowledge, Science, } \\
\text { Coverage }\end{array}$ \\
\hline 8 & $\begin{array}{l}\text { Computer-mediated } \\
\text { communication }\end{array}$ & 39 & $\begin{array}{l}\text { Computer-mediated communication, } \\
\text { Bias, Effect, Group, Cue }\end{array}$ \\
\hline 9 & Organizational communication & 34 & $\begin{array}{l}\text { Management, Performance, Value, } \\
\text { Determinant, Diversity }\end{array}$ \\
\hline 10 & $\begin{array}{l}\text { Racism and the media in the } \\
\text { United States }\end{array}$ & 34 & $\begin{array}{l}\text { Race, judgment, Stereotype, Process, } \\
\text { accessibility }\end{array}$ \\
\hline
\end{tabular}

Table 2. Description of the clusters mapped in the Communication category during the decade 2001-2010.

\section{Thematic structure in Communication during the decade from 2011-2020}

The bibliometric map for the decade 2011-2020 comprises 1,876 words, which are grouped into 11 thematic clusters (see Figure 2 and Table 3 ). The clusters identified during this second decade are described below. 


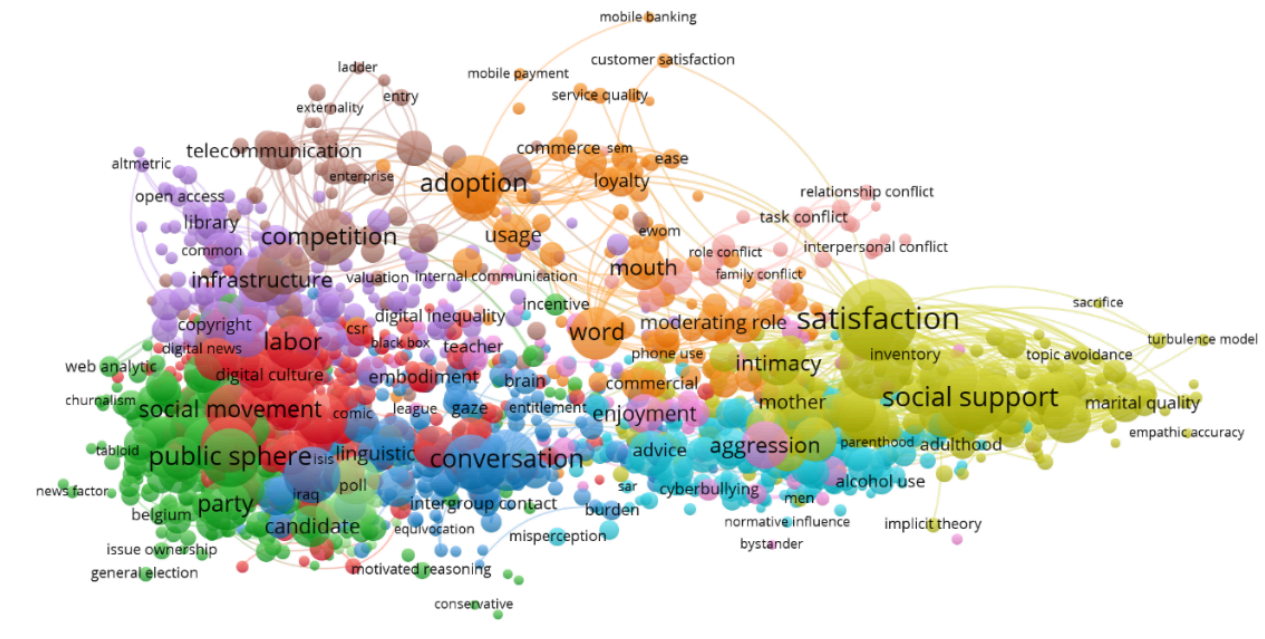

B

Figure 2. Thematic map of the field Communication during the decade 2011-2020.

- Cluster 1 "Global communication". This first cluster is the most extensive on the entire map, and it is also the most heterogeneous. It is made up of 416 terms that highlight the most global studies of communication. The heterogeneity of this cluster is also denoted by the presence of a group of terms related to gender studies.

- Cluster 2 "Political communication and digital journalism". This is the second-largest cluster on the entire map, which is made up of 337 keywords. Among the terms that most represent the studies on political communication are election campaign, politician, political party, Trump, parliament, vote, and many others. While among the most representative keywords of digital journalism and alternative communication media are fake news, digital journalism, online journalism, disinformation, journalism study, journalism practice, online newspaper, post-truth, journalistic practice, and others.

- Cluster 3 "Speech and language". This cluster is made up of 246 keywords that represent studies on speech and language.

- Cluster 4 "Communication and human psychology: mental health and interpersonal relationships". This cluster comprises 191 keywords that represent the dimension of mental health and interpersonal relationships in the area of human communication and health.

- Cluster 5 "Scholarly publishing". This cluster groups 186 words that reflect studies on academic publications. There is a prevalence of terms related to the academic editorial context and the field of information science due to terms such as journal, archive, library, publishing, documentation, and many other related terms.

- Cluster 6 "Health communication". This cluster, made up of 185 words, highlights the theme related to communication studies in the context of medicine and health.

- Cluster 7 "Commercial communication". 113 keywords are grouped in this cluster that has to do with business strategies, brand positioning, products, and marketing communication.

- Cluster 8 "Telecommunication". This cluster of 75 keywords represents an area with a technological focus since it deals with telecommunications, mobile telephony, and technological means for communication.

- Cluster 9 "Communication and human psychology: crime and violence". This cluster 
of 52 keywords represents the area of crimes, aggressive behavior, and cyberbullying in the media.

- Cluster 10 “Organizational communication”. This cluster, made up of 41 keywords, has to do with managing communication in organizational environments. Here the presence of concepts related to conflict management, mediating role, internal communication, and organizational culture stands out.

- Cluster 11 "Science communication". This last cluster of the second decade is composed of 34 keywords that reflect the theme related to science communication, public understanding of science, science journalism, and science education.

\begin{tabular}{llll}
\hline Cluster & \multicolumn{1}{c}{ Topic } & Keywords & \multicolumn{1}{c}{ Top co-occurring keywords } \\
\hline 1 & Global communication & 416 & $\begin{array}{l}\text { Protest, labor, social movement, } \\
\text { Feminism, photography }\end{array}$ \\
2 & & $\begin{array}{l}\text { Public sphere, mediatization, party, } \\
\text { objectivity, candidate }\end{array}$ \\
journalism & 337 & $\begin{array}{l}\text { Conversation, critical discourse } \\
\text { analysis, conversation analysis, }\end{array}$ \\
question, multimodality
\end{tabular}

Table 3. Description of the clusters mapped in the Communication category during the decade 2001-2010. 


\section{DISCUSSION}

The field of communication, examined from the articles included in the JCR-2019 edition in the Communication category, has undergone considerable transformations during the first two decades of the 21st century. After mapping the most representative keywords of each decade, four very stable and delineated themes are evidenced in both decades: the themes of discourse and language, commercial communication, health communication, and organizational communication.

In another sense, four thematic groups were merged. For example, the technological dimension was present in both decades but with a different thematic orientation. During the first decade, two clusters related to technology, Cluster 1. Technology and communication in social media, and Cluster 8. Computer-mediated communication; but only one technological cluster was visualized for the second decade, Cluster 8. Telecommunications (see Table 3 ). As part of the transition from the first to the second decade, the topic on Media and addiction (see Cluster 4 in Table 2) was extended to more in-depth studies on the relationship of psychology with communication, specifically in the study of not only addictions but also mental health and interpersonal relationships (see Cluster 4 in Table 3). Another thematic shift took place regarding political and scientific communication. Although this was a visible theme in the bibliometric map (see Figure 1), in the second decade, scientific and political communication are separated thematically. In 2011-2020, political communication was closely linked to digital journalism, while science communication forms an independent subject area. The last topic that underwent substantial changes was related to Racism and the media in the United States. This theme was viewed independently during the first decade; however, in the second decade, it joined Cluster 1. Global communication, which has a high level of heterogeneity due to the diversity of keywords.

The longitudinal bibliometric analysis displayed the appearance of new themes in the second decade and a better delineation of others that in the first decade appeared co-grouped in the same cluster. Such is the case of the scholarly publishing theme (Cluster 5 in Table 3 ). The processes associated with scientific publications, open science, peer review, open access, copyright, among others, are studied. This cluster highlights the high frequency of the keyword Spain, which represents a geographic context. In this regard, it should be noted the high volume of articles published on the subject in the Spanish journals Comunicar, and Profesional de la Información, both of which have favored a better delineation of this subject.

Somehow, in the first decade analyzed, themes with a socio-psychological dimension were evidenced (e.g., Cluster 4. Media and addiction, and Cluster 10. Racism in the USA); but in this second decade, this dimension acquires greater representation due to the presence of two clusters on Communication and human psychology; but with two different orientations. One was mentioned earlier (Cluster 4 in Table 2), while the other emerged in this last decade and is geared towards crime and violence. Finally, the independence acquired by the Science communication cluster (Cluster 11 in Table 3), which was linked to cluster 7 during the first decade (see Table 2), is evidenced. It is worth mentioning the presence of journals devoted merely to science communication in the JCR 2019, such as Science Communication and Public Understanding of Science, -regardless of the cross-disciplinary character of this topic-.

\section{CONCLUDING REMARKS}

This study made it possible to show the thematic evolution of the field of Communication from a group of journals listed in the JCR 2019 in WoS. The mapping of terms in bibliometric 
networks found that there are four predominant themes in both decades analyzed (Speech and Language, Commercial Communication, Health Communication, and Organizational Communication). While there were four topics with a high level of fusion, reflecting the exclusive formation of important research areas during the second decade (2011-2020), such as science communication, scholarly publishing, mental health and interpersonal relationships, and crime and violence. From a macro perspective, it was visualized that the technological dimension was no longer so predominant from the first to the second decade. Instead, there was a more significant presence of themes that respond to the socio-psychological dimension.

\section{REFERENCES}

Beatty, M.J., Feeley, T.H., \& Dodd, M.D. (2012). Journal impact factor or intellectual influence? A content analysis of citation use in Communication Monographs and Human Communication Research (2007-2009). Public Relations Review, 38(1), 174-176. https://doi.org/10.1016/j.pubrev.2011.08.005

Chan, C.H., \& Grill, C. (2020). The highs in communication research: Research topics with high supply, high popularity, and high prestige in high-impact journals. Communication Research, 0093650220944790. https://doi.org/10.1177\%2F0093650220944790

Comfort, S.E., \& Park, Y.E. (2018). On the field of environmental communication: A systematic review of the peer-reviewed literature. Environmental Communication, 12(7), 862-875. https://doi.org/10.1080/17524032.2018.1514315

Donthu, N., Kumar, S., \& Pattnaik, D. (2021). Intellectual structure and publication pattern in International Journal of Advertising: a bibliometric analysis during 1982-2019. International Journal of Advertising, 40(2), 148-174. https://doi.org/10.1080/02650487.2020.1756655

Feeley, T.H. (2008). A bibliometric analysis of communication journals from 2002 to 2005. Human communication research, 34(3), 505-520. https://doi.org/10.1111/ j.1468-2958.2008.00330.x

Feng, G. C. (2020). Determinants of institutional excellence in Asian communication research. Asian Journal of Communication, 30(6), 389-408. https://doi.org/10.1080/ 01292986.2020 .1833952

Ji, Y. G., Tao, W., \& Rim, H. (2021). Theoretical Insights of CSR Research in Communication from 1980 to 2018: A Bibliometric Network Analysis. Journal of Business Ethics, 1-23. https://doi.org/10.1007/s10551-021-04748-w

Kim, J., Kang, S., \& Lee, K.H. (2019). Evolution of digital marketing communication: Bibliometric analysis and network visualization from key articles. Journal of Business Research. https://doi.org/10.1016/j.jbusres.2019.09.043

Lee, C. J., \& Sohn, D. (2016). Mapping the social capital research in communication: A bibliometric analysis. Journalism \& Mass Communication Quarterly, 93(4), 728-749. https://doi.org/10.1177\%2F1077699015610074

Lee, K., Jung, H., \& Song, M. (2016). Subject-method topic network analysis in communication studies. Scientometrics, 109(3), 1761-1787. https://doi.org/10.1007/ 
Lin, J., \& Lee, S.T. (2012, November). Mapping 12 years of communication scholarship: themes and concepts in the Journal of Communication. In International Conference on Asian Digital Libraries (pp. 359-360). Springer, Berlin, Heidelberg. https://doi.org/10.1007/ 978-3-642-34752-8_53

López-Robles, J.R., Guallar, J., Otegi-Olaso, J.R., \& Gamboa-Rosales, N.K. (2019). El profesional de la información (EPI): bibliometric and thematic analysis (2006-2017). El profesional de la información, 28(4), e280417. https://doi.org/10.3145/epi.2019.jul.17

Mheidly, N., \& Fares, J. (2020). Health communication in low-income countries: a 60-year bibliometric and thematic analysis. Journal of Education and Health Promotion, 9. https://dx.doi.org/10.4103\%2Fjehp.jehp_384_20

Miguez-Gonzalez, M.I., \& Costa-Sanchez, C. (2019). Organizational communication research trends: Contributions by Spanish authors in indexed journals (2014-2018). Profesional de la Informacion, 28(5). https://doi.org/10.3145/epi.2019.sep.10

Montero-Díaz, J., Cobo, M., Gutiérrez-Salcedo, M., Segado-Boj, F., \& Herrera-Viedma, E. (2018). A science mapping analysis of 'Communication' WoS subject category (1980-2013). Comunicar, 55(2), 81-91. https://doi.org/10.3916/C55-2018-08

Rains, S.A., Keating, D.M., Banas, J.A., Richards, A.S., \& Palomares, N.A. (2020). The state and evolution of communication research: A topic modeling analysis of 20,000 journal article abstracts from 1918-2015. Computational Communication Research, 2(2), 203-234. https://doi.org/10.5117/CCR2020.2.004.RAIN

van Eck, N.J., Waltman, L., Dekker, R., \& van den Berg, J. (2010). A comparison of two techniques for bibliometric mapping: Multidimensional scaling and VOS. Journal of the American Society for Information Science and Technology, 61(12), 2405-2416. https://doi.org/ 10.1002/asi.21421

van Osch, W., \& Coursaris, C. K. (2014). Social media research: An assessment of the domain's productivity and intellectual evolution. Communication Monographs, 81(3), 285-309. https://doi.org/10.1080/03637751.2014.921720 